\title{
Lens Injury Stimulates Axon Regeneration in the Mature Rat Optic Nerve
}

\author{
Steven Leon, ${ }^{1,2}$ Yuqin Yin,, ${ }^{1,2}$ Jennifer Nguyen, ${ }^{1}$ Nina Irwin,, ${ }^{1,2}$ and Larry I. Benowitz ${ }^{1,2,3}$ \\ ${ }^{1}$ Department of Neurosurgery, Children's Hospital, ${ }^{2}$ Department of Surgery, and 3 Program in Neuroscience, Harvard \\ Medical School, Boston Massachusetts 02115
}

In mature mammals, retinal ganglion cells (RGCs) are unable to regenerate their axons after optic nerve injury, and they soon undergo apoptotic cell death. However, a small puncture wound to the lens enhances RGC survival and enables these cells to regenerate their axons into the normally inhibitory environment of the optic nerve. Even when the optic nerve is intact, lens injury stimulates macrophage infiltration into the eye, Müller cell activation, and increased GAP-43 expression in ganglion cells across the entire retina. In contrast, axotomy, either alone or combined with intraocular injections that do not infringe on the lens, causes only a minimal change in GAP-43

The primary visual pathway has been widely used as a model system to investigate neuronal survival and axon regeneration after CNS injury. In the optic nerve, as in other CNS pathways, severed axons show a transient local sprouting reaction but no long-range growth (Ramon y Cajal, 1991). Moreover, if axotomy occurs within the orbit, retinal ganglion cells (RGCs) undergo apoptotic cell death after a delay of a few days (Villegas-Perez et al., 1988; Berkelaar et al., 1994). Both cell death and regenerative failure can be altered by manipulating extracellular conditions. Intravitreal injections of brain-derived neurotrophic factor (BDNF), neurotrophin- (NT-) 4/5, ciliary neurotrophic factor (CNTF), glial-derived neurotrophic factor (GDNF), and other polypeptide growth factors enhance RGC survival after nerve crush, although this effect is transient (Carmignoto et al., 1989; Mey and Thanos, 1993; Cohen et al., 1994; Mansour-Robaey et al., 1994; Rabacchi et al., 1994; Di Polo et al., 1998; Koeberle and Ball, 1998). In culture, isolated RGCs require a combination of insulin (or IGF-2), CNTF (or LIF), BDNF (or NT-4/5), and elevated intracellular cAMP for their survival (Meyer-Franke et al., 1995). cAMP, through protein kinase A activation, augments the effects of growth factors by causing their receptors to translocate to the cell surface (Meyer-Franke et al., 1998), and similar effects are seen in vivo (Shen et al., 1999). Even in the absence of polypeptide growth factors, long-term survival can be maintained in vivo by overexpressing the anti-apoptotic protein Bcl-2 (Bon-

\footnotetext{
Received Jan. 31, 2000; revised March 30, 2000; accepted March 30, 2000.

This work was supported by National Institutes of Health Grant EY 05690 (L.B.), The Glaucoma Research Foundation, Boston Life Sciences, Inc., and the Boston Neurosurgical Foundation. We thank Professor Martin Berry (United Medical and Dental Schools, Guy's Campus, London, UK) for instruction in surgical methods and helpful discussions and Isaac Benowitz (Columbia University) for deriving the formula to calculate total axon counts.

S.L. and Y.Y. contributed equally to this work.

Correspondence should be addressed to Dr. Larry I. Benowitz, Laboratories for Neuroscience Research in Neurosurgery, Children's Hospital, 300 Longwood Avenue, Boston, MA 02115. E-mail: benowitz@a1.tch.harvard.edu.

Copyright (C) 2000 Society for Neuroscience $0270-6474 / 00 / 204615-12 \$ 15.00 / 0$
}

expression in RGCs and a minimal activation of the other cell types. Combining nerve injury with lens puncture leads to an eightfold increase in RGC survival and a 100-fold increase in the number of axons regenerating beyond the crush site. Macrophage activation appears to play a key role, because intraocular injections of Zymosan, a yeast cell wall preparation, stimulated monocytes in the absence of lens injury and induced RGCs to regenerate their axons into the distal optic nerve.

Key words: regeneration; optic nerve; lens; retinal ganglion cell; macrophages; axon; GAP-43; Müller cell; BDNF; glaucoma

fanti et al., 1996) or by limiting caspase activity (Kermer et al., 1998). Enhanced survival by itself is insufficient to assure axon regeneration, however, because Bcl-2-overexpressing mice show almost no axon growth past the site of nerve injury (Chierzi et al., 1999).

RGCs can regenerate their axons in vivo through a peripheral nerve graft (So and Aguayo, 1985; Aguayo et al., 1987; Bray et al., 1987). This result has generally been interpreted as showing that, although these neurons are intrinsically capable of regenerating their axons, this can only occur outside the inhibitory influences that normally prevail in the CNS. However, more recent studies show that RGCs can extend axons into the optic nerve itself if a fragment of peripheral nerve is implanted into the vitreous (Berry et al., 1996). More modest axon growth into the optic nerve has been achieved by inactivating the small GTPase Rho (Lehmann et al., 1999).

In the course of studying the effects of various agents on axon growth, we discovered that intraocular injections that infringe on the lens initiate a set of cellular changes that includes macrophage infiltration, astrocyte stimulation, and increased expression of the growth-associated protein GAP-43 in RGCs. As a consequence of these changes, RGCs show improved survival and unprecedented levels of axon growth into the normally prohibitive environment of the optic nerve.

\section{MATERIALS AND METHODS}

Optic nerve surgery and intraocular injections. Surgical procedures were based on those described previously (Berry et al., 1996) and were approved by the Children's Hospital Animal Care and Use Committee. Adult male Fisher rats (Charles River Laboratories, Wilmington, MA), 250-350 gm, were kept in a pathogen-controlled environment in standard cages and were allowed to feed ad libitum. Animals were sedated by methoxyflurane inhalation (Schering-Plow, Union, $\mathrm{NJ}$ ) and anesthetized with an intraperitoneal injection of ketamine $(60-80 \mathrm{mg} / \mathrm{kg}$ : Phoenix Pharmaceutical, St. Joseph, MO) and xylazine (10-15 mg/kg: Bayer, Shawnee Mission, KA). After the head was shaved, rats were positioned in a stereotaxic apparatus (Kopf Instruments, Tujunga, CA) and a 1-1.5 

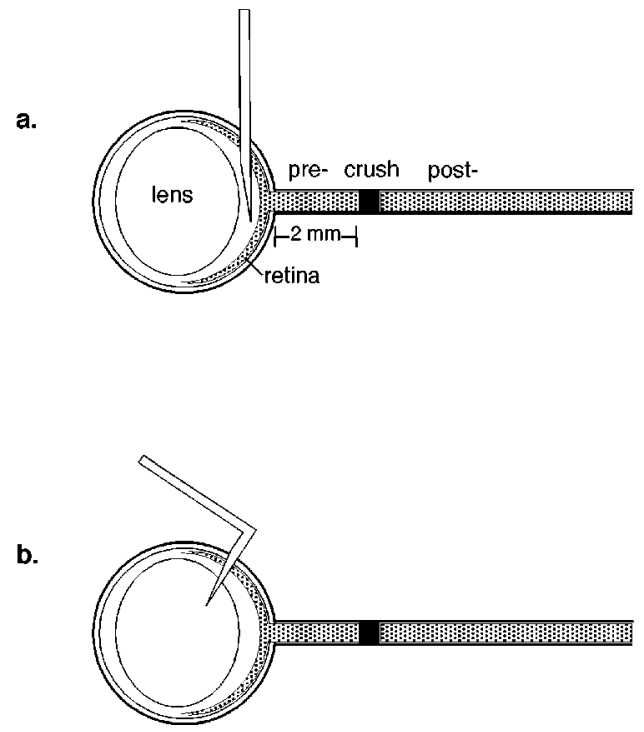

Figure 1. Surgical approaches. Optic nerves were crushed $2 \mathrm{~mm}$ from the eye. Intraocular injections were made either $(a)$ vertically into the vitreous chamber to avoid puncturing the lens or $(b)$ with a bent needle to puncture the lens to a depth of $\sim 0.5 \mathrm{~mm}$.

$\mathrm{cm}$ incision was made in the skin above the right orbit. Under microscopic illumination, the lachrymal glands and extraocular muscles were resected to expose 3-4 $\mathrm{mm}$ of the optic nerve. The epineurium was slit open along the long axis, and the nerve was crushed $2 \mathrm{~mm}$ behind the eye with angled jeweler's forceps (Dumont \# 5) for $10 \mathrm{sec}$, avoiding injury to the ophthalmic artery. Nerve injury was verified by the appearance of a clearing at the crush site, while the vascular integrity of the retina was evaluated by fundoscopic examination. Cases in which the vascular integrity of the retina was in question were excluded from the study.

For intraocular injections, the globe was retracted with a mosquito snap to expose its posterior aspect. In some cases, injections were made through the sclera and retina with a 30 gauge needle $1-2 \mathrm{~mm}$ superior to the optic nerve head, inserting the tip of the needle perpendicular to the axis of the nerve to a depth of $2 \mathrm{~mm}$ without infringing on the lens (minimally invasive injection; Fig. $1 a$ ); in other cases, the tip of the needle was bent at a $90^{\circ}$ angle and inserted into the eye $2 \mathrm{~mm}$ above the nerve head, perpendicular to the sclera, to intentionally puncture the lens surface (Fig. 1b). Lens injury was confirmed by direct visualization through the cornea; further verification of lens injury was an opacification that occurred within 1 week. Injection volumes were $5 \mu \mathrm{l}$ using saline as a vehicle; in some cases, we examined the effects of needle puncture alone without injections. Survival times ranged from 1 to $40 \mathrm{~d}$.

Groups included controls with no surgery $(n=3)$, animals with lens puncture but no nerve crush $(n=11)$, animals with nerve crush and either no intraocular surgery $(n=24)$ or a single puncture of the lens $(n=24)$; animals with nerve crush and an anterior lens puncture at the limbus $(n=4)$ or with multiple posterior punctures of the lens $(n=3)$; animals with nerve crush and a single injection of either recombinant rat CNTF $(5 \mu \mathrm{g} / \mathrm{ml}$; Alamone Labs, Jerusalem, Israel; $n=5$; or $10 \mu \mathrm{g} / \mathrm{ml}$; Promega, Madison, WI; $n=5$ ), an anti-rat CNTF polyclonal antibody $(20 \mu \mathrm{g} / \mathrm{ml}$; R \& D Systems, Minneapolis, MN; $n=4)$, basic fibroblast growth factor $(5 \mu \mathrm{g} / \mathrm{ml}$; kindly provided by Dr. Patricia D'Amore, Children's Hospital Boston, MA; $n=3$ ), anti-bovine basic fibroblast growth factor (bFGF) (1-5 mg/ml; Upstate Biotechnology, Lake Placid, $\mathrm{NY} ; n=4)$, anti-BDNF ( $5 \mathrm{mg} / \mathrm{ml} ; \mathrm{R} \& \mathrm{D}$; mouse monoclonal; $n=4)$ or $0.9 \% \mathrm{NaCl}(n=4)$. Animals showing signs of intravitreal hemorrhage after puncture were excluded.

Sciatic nerve implants. Pre-degenerated peripheral nerve fragments were obtained by performing a crush injury on the peroneal branch of the sciatic nerve. Four days later, rats were killed with an overdose of ketamine plus xylazine, and the portion of the nerve distal to the crush site was dissected out. As described previously (Berry et al., 1996), sections of sciatic nerve $\sim 1 \mathrm{~mm}$ in length were implanted into host animals that had undergone optic nerve surgery as described above $(n=$ 5). Fragments were inserted by cutting a small radial slit through the sclera and implanting a single piece of tissue into the vitreous, taking care to avoid injuring the lens.

Preparation for histology. At survival times ranging from 1 to $40 \mathrm{~d}$, animals were given a lethal overdose of anesthesia and perfused through the heart with ice-cold PBS plus heparin $(10,000 \mathrm{U}$ in $100 \mathrm{ml})$ followed by $4 \%$ paraformaldehyde in PBS $(100 \mathrm{ml})$. Eyes with nerve segments up to the optic chiasm still attached were dissected free from connective tissue, post-fixed in $4 \%$ paraformaldehyde (overnight, $4^{\circ} \mathrm{C}$ ) and transferred to a $30 \%$ sucrose solution (overnight, constant rocking, $4^{\circ} \mathrm{C}$ ). Frozen sections (15 $\mu \mathrm{m}$ thickness) were cut longitudinally on a cryostat, thaw-mounted onto coated glass slides (Superfrost Plus; Fisher Scientific, Houston, TX), and stored at $-80^{\circ} \mathrm{C}$ until further use.

Immunohistochemistry. Sections were stained with antibodies to visualize either the neuronal growth-associated protein GAP-43; glial fibrillary acidic protein (GFAP); ED-1, a marker for activated cells of monocyte lineage; or myelin basic protein (MBP). GAP-43 was visualized using the IgG fraction of an antibody prepared in sheep (Benowitz et al., 1988), followed by either a biotin- or fluorescein-conjugated secondary antibody. In the former case, sections were preincubated with $0.3 \% \mathrm{H}_{2} \mathrm{O}_{2}$ in $100 \%$ methanol (30 min), blocked with $5 \%$ rabbit serum in Trisbuffered saline (TBS, $\mathrm{pH} 7.4,1 \mathrm{hr}$ ), and incubated in the primary antibody at a 1:50,000 dilution (in TBS containing $300 \mathrm{~mm} \mathrm{NaCl}, 2 \%$ BSA, and $0.1 \%$ Tween $20: \mathrm{TBS}_{2} \mathrm{~T}$; overnight, $4^{\circ} \mathrm{C}$, constant rocking). Sections were rinsed $\left(3 \times\right.$ over a $4 \mathrm{hr}$ period in $\left.\mathrm{TBS}_{2} \mathrm{~T}\right)$, incubated in biotinylated rabbit anti-sheep IgG (1:250 in $\mathrm{TBS}_{2} \mathrm{~T}$; Vector Laboratories, Burlingame, CA), rinsed $3 \times$, and reacted with avidin-biotin-HRP complex for $1 \mathrm{hr}$ (as per the manufacturer's protocol; Vector Laboratories) followed by diaminobenzidine (DAB) enhanced with $\mathrm{NiCl}_{2}$ (Vector Laboratories). In cases in which GAP-43 was viewed by immunofluorescence, similar conditions were used except that the primary antibody was diluted 1:2500, and the secondary antibody was a fluorescein-conjugated anti-sheep IgG made in rabbit (1:500; Vector Laboratories). In cases in which GAP-43 was visualized together with other antigens, we used a mouse monoclonal anti-GAP-43 antibody (clone 9-1E12; 1:250 dilution; Boehringer-Mannheim, Indianapolis, IN) followed by a fluoresceinconjugated anti-mouse IgG made in horse (Vector Laboratories; 1:500). Immunofluorescent sections were covered using Vectashield (Vector Laboratories) as a mounting medium. To detect changes in Müller cells, we used a rabbit anti-GFAP antibody (Sigma, St. Louis, MO; 1:7500) and a biotinylated goat anti-rabbit $\operatorname{IgG}(1: 500)$. Reactive macrophages were visualized with the ED-1 antibody (Serotec, Oxford, UK; 1:200 dilution) and biotinylated horse anti-mouse IgG (Vector Laboratories; 1:500). Myelin was visualized in the optic nerve using a rabbit anti-MBP antibody (1:25, Zymed, San Francisco, CA) followed by a Texas Redconjugated goat anti-rabbit IgG (1:500; Vector Laboratories).

Quantitation of axon growth. Axon growth was quantified by counting the number of GAP-43-positive axons extending 0.5 and $1 \mathrm{~mm}$ from the end of the crush site in four sections per case. The cross-sectional width of the nerve was measured at the point at which the counts were taken and was used to calculate the number of axons per millimeter of nerve width. The number of axons per millimeter was then averaged over the four sections. $\Sigma \mathrm{a}_{\mathrm{d}}$, the total number of axons extending distance $d$ in a nerve having a radius of $r$, was estimated by summing over all sections having a thickness $t(15 \mu \mathrm{m})$ :

$$
\Sigma a_{\mathrm{d}}=\pi r^{2} \times[\text { average axons } / \mathrm{mm}] / t
$$

Anterograde labeling. We used cholera toxin B fragment (CTB) as an anterograde tracer to verify that axons visualized in the distal optic nerve originated in RGCs. Animals that underwent nerve crush, either with or without lens puncture, were injected with CTB $(2.5 \mu \mathrm{g} / \mu \mathrm{l}$ in $5 \mu \mathrm{l}$ PBS $) 20 \mathrm{~d}$ after the original surgery. Animals were killed and prepared for histology the following day as described above. Slide-mounted sections were reacted with an antibody to CTB (made in goat; List Biologic, Campbell, CA; 1:40,000 dilution), followed by a rabbit anti-goat IgG secondary antibody (Vector Laboratories; 1:500 dilution). In some cases, GAP-43 and CTB were examined together, using a monoclonal anti-GAP-43 antibody made in mouse and the goat anti-CTB antibody (1:250), followed with the appropriate secondary antibodies conjugated to fluorescein and Texas Red, respectively (Vector Laboratories, 1:500). 


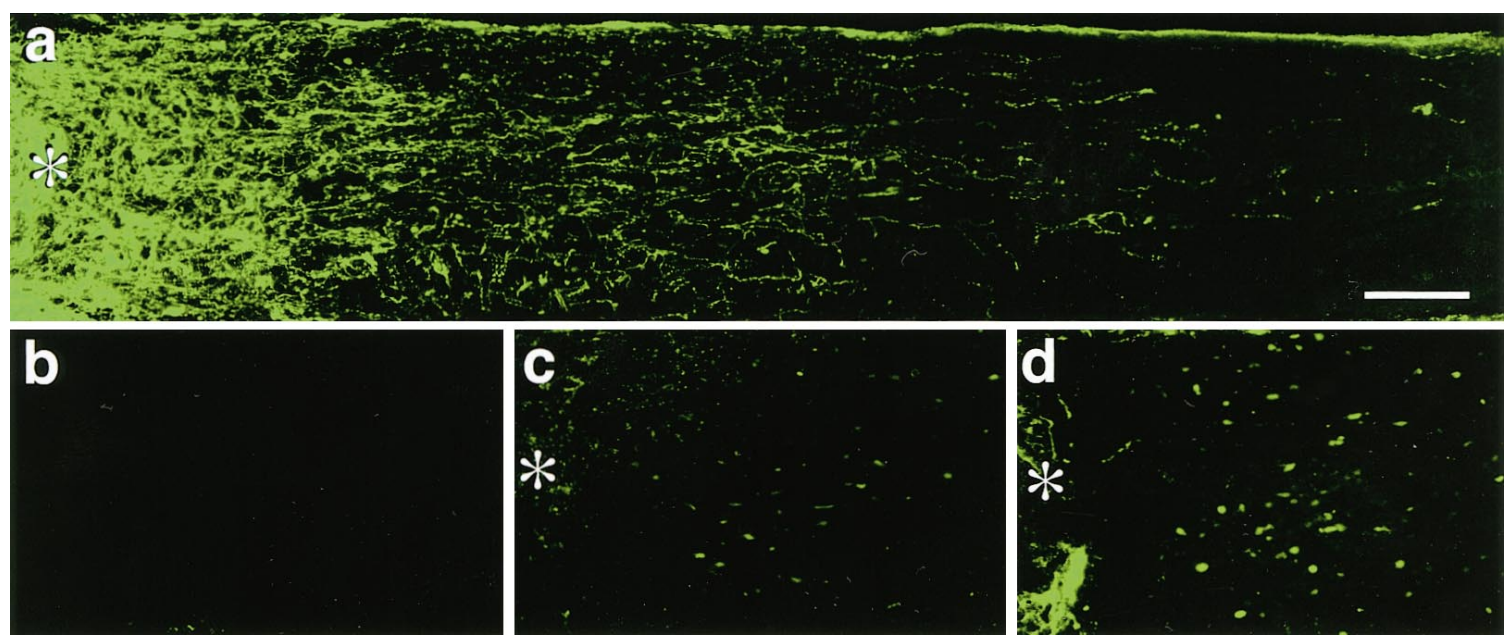

Figure 2. Lens puncture stimulates axon regeneration in the optic nerve. $a$, A combination of nerve crush plus lens puncture stimulates RGCs to extend GAP-43-positive fibers through the injury site $\left(^{*}\right)$ and several millimeters into the distal portion of the optic nerve. Controls show no GAP-43 in the normal nerve $(b)$ and very little immunostaining in the distal optic nerve after crush injury alone $(c)$ or after nerve crush with a minimally invasive injection that does not infringe on the lens $(d)$. Scale bar, $100 \mu \mathrm{m} ; a, c$, and $d$ are $21 \mathrm{~d}$ after nerve crush.

Quantitation of cell survival. For cell survival studies, RGCs were retrogradely labeled with Fluorogold (Fluorochrome, Inc., Denver, CO) $7 \mathrm{~d}$ before nerve crush. Rats were anesthetized as above, a midline incision was made in the scalp, and a bone flap was opened above the occipital cortex. Posterior cortex was vacuum-aspirated, and multiple injections of Fluorogold $(5 \mu \mathrm{g} / \mathrm{ml}$ in PBS containing 1\% DMSO, $1 \mu$ l per injection) were made into the superior colliculi (depth, $\sim 1 \mathrm{~mm}$ ). Gelfoam $\left(1 \mathrm{~mm}^{3}\right.$; Upjohn, Kalamazoo, MI) soaked in the same Fluorogold solution was inserted over the colliculus. One week later, animals received an optic nerve crush combined with either a lens puncture or a minimally invasive intraocular injection. Normal controls $(n=5)$ were labeled to obtain baseline values of RGC density.

Twenty-one days after nerve crush and intraocular injections (i.e., $28 \mathrm{~d}$ after Fluorogold labeling), animals were killed with an overdose of ketamine plus xylazine, and the retinas were dissected without fixation. After making a radial slit, retinas were placed onto nylon filters attached to microscope slides, overlaid with filter paper soaked in $4 \%$ paraformaldehyde (in PBS), and held down with weights on the edges for $1 \mathrm{hr}$. Retinas were then removed from the filters, flat-mounted, and covered using Vectashield. Under fluorescent illumination (200× magnification), six regions, radially distributed at 1 and $2 \mathrm{~mm}$ from the optic nerve head, were counted for labeled RGCs using a $10 \times 10$ grid $\left(0.16 \mathrm{~mm}^{2}\right)$. Counts were averaged across the six regions.

Western blotting for GAP-43 and GFAP. Fourteen days after optic nerve crush, unfixed retinas were freshly dissected and solubilized in $100 \mu \mathrm{l}$ of $2 \times$ SDS-PAGE sample buffer (O'Farrell, 1975). Samples were balanced for protein content and separated by SDS-PAGE in mini-gels (Bio-Rad, Hercules, CA). Proteins were transferred to PVDF membranes $(0.45 \mu \mathrm{m}$ pore; Millipore, Bedford, MA) and probed using antibodies to either GAP-43 or GFAP. In the former case, the staining protocol closely followed that used for tissue, except that the concentration of monoclonal anti-GAP-43 antibody (Boehringer Mannheim) was 1:1000; in the case of GFAP, the primary antibody was used at a concentration of 1:5000. Secondary antibodies were HRP-conjugated. Immunoreactivity was detected with ECL reagent (Amersham, Arlington Heights, IL) and fluorography.

Macrophage activation. Several methods were attempted to stimulate macrophages in the eye without puncturing the lens. These included injecting interferon- $\gamma$ (IFN- $\gamma$; Life Technologies, Gaithersburg, MD; $5000 \mathrm{U}$ in $5 \mu \mathrm{l} ; n=5$ ) at a dosage sufficient to activate monocytes throughout the nervous system (Sethna and Lampson, 1991); or Zymosan (625 $\mu \mathrm{g}$ in $5 \mu \mathrm{l}$; Sigma; $n=5)$, a yeast cell wall preparation (Stewart and Weir, 1989; Ross and Vetvicka, 1993; Lombard et al., 1994; Fitch et al., 1999). We also introduced activated macrophages, obtained from donor animals by injecting $\mathrm{Ca}^{2+}$ - and $\mathrm{Mg}^{2+}$-free buffer containing $0.025 \%$ trypsin and $2 \mathrm{~mm}$ EDTA into the peritoneal cavity as described (Smith and Hale, 1997); after 3 min, the cavity was opened, and fluid was removed and added to DMEM (Sigma) containing 1\% fetal bovine serum (Gemini Bio-Products, Calabasas, CA). Cells were collected by centrifugation, resuspended in the same medium, plated in culture dishes, and incubated $4 \mathrm{hr}$. After washing off nonadherent cells, the remaining cells were removed with trypsin, added to culture media, collected by centrifugation, and washed with saline. The presence of activated macrophages was verified by staining cells with ED-1 and OX-42 antibodies (Serotec). Approximately $10^{5}$ macrophages were injected into a host vitreous, with care taken to avoid injuring the lens $(n=4)$. To suppress macrophage activation after lens puncture, we used the tripeptide microglial inhibitory factor (MIF; estimated final concentration in eye, $50 \mu \mathrm{M}$; Sigma; $n=6$ ), Ciglitazone (estimated final concentration in eye, $75 \mu \mathrm{M}$; Biomol, Plymouth Meeting, PA; $n=4$ ), or prostaglandin $\mathrm{J} 2$ (estimated final concentration in eye, $80 \mu \mathrm{M}$; Calbiochem, La Jolla, CA; $n=3$ ).

\section{RESULTS}

\section{Axon outgrowth}

Because RGCs only express GAP-43 during axon outgrowth, probes for this protein enable one to visualize RGCs in a growth state (Meiri et al., 1986; Moya et al., 1988; Doster et al., 1991; Schaden et al., 1994; Berry et al., 1996). In animals having a nerve crush combined with lens puncture, numerous GAP-43-positive axons grew past the injury into the distal optic nerve (Fig. $2 a$ ). As expected, intact, normal optic nerves showed no staining at all (Fig. 2b). Animals with nerve crush but with either no intraocular injections (Fig. $2 c$ ) or intraocular injections that did not infringe on the lens (Fig. 2d) showed some GAP-43 immunostaining in the 


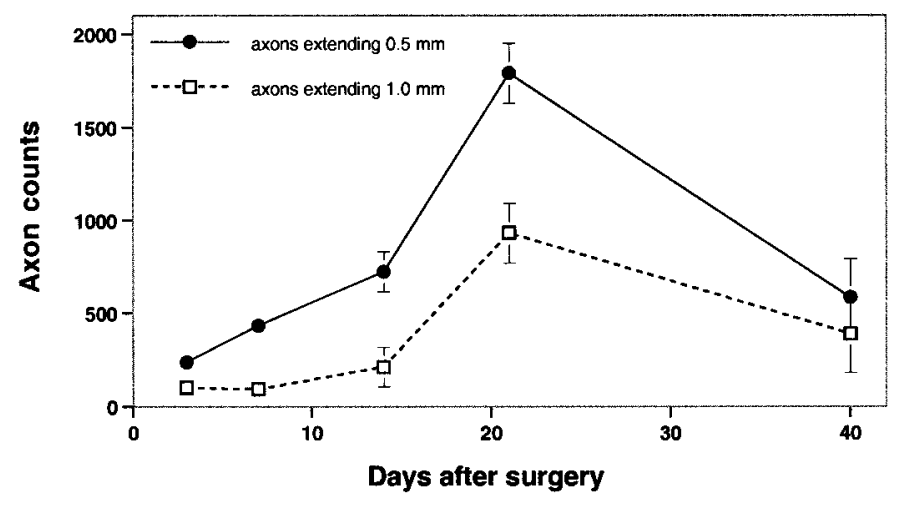

Figure 3. Time course of axon growth into the distal optic nerve. After nerve crush combined with lens puncture, the number of axons extending 0.5 or $1.0 \mathrm{~mm}$ distal to the injury site rises continuously over the first three weeks, then declines.

proximal region of the nerve (see below) and in the neuroma that forms at the injury site, but almost none beyond this point. Quantitatively, animals with optic nerve crush alone $(n=5)$ averaged $4 \pm 3$ axons (mean \pm SEM) extending $0.5 \mathrm{~mm}$ past the crush site, and none at $1 \mathrm{~mm}$; animals in which the nerve was crushed but which received minimally invasive injections $(n=7)$ had only slightly more growth $(22 \pm 9$ axons at $0.5 \mathrm{~mm}$, and $6 \pm$ 3 at $1 \mathrm{~mm}$ ). Relative to the latter group, animals in which the nerve was crushed and the lens punctured showed a nearly 100fold increase in axon growth $(1791 \pm 232$ axons at $0.5 \mathrm{~mm}$, and $933 \pm 162$ axons at $1 \mathrm{~mm}$ distal to the crush site, $n=6$; see Fig. 10). The difference between the latter group and controls with nerve crush plus minimally invasive injections was highly significant $(p<0.001$ at both 0.5 and $1.0 \mathrm{~mm})$.

If GAP-43-immunopositive processes truly represent growing axons, we would expect to see a progressive increase in their numbers over time. As shown in Figure 3, the number of axons reaching 0.5 or $1 \mathrm{~mm}$ past the injury site rose continuously over the first 3 weeks. By 40 d, however, the number declined, suggesting that GAP-43 expression in RGCs had diminished or that some of the axons that had been present at 3 weeks degenerated.

\section{Anterograde labeling with cholera toxin}

Anterograde labeling afforded a more rigorous way to demonstrate that axons distal to the crush site arose from RGCs. For these studies, we injected CTB into the posterior chamber $1 \mathrm{~d}$ before killing animals, then performed immunohistochemistry to detect CTB in the optic nerve. The pattern of CTB staining closely resembled that for GAP-43. After nerve crush without lens puncture, CTB-positive axons were detected proximal to the injury site but not beyond it, whereas with nerve crush plus lens puncture, many CTB-positive axons appeared in the distal nerve. Double-labeling revealed that axonal elements growing beyond the crush site contained both antigens, and in some cases, intense double-labeling was observed in structures resembling growth cones (Fig. 4c, arrowhead). In four CTB-labeled animals having optic nerve crush and lens puncture, we counted $903 \pm 54$ axons at $0.5 \mathrm{~mm}$ with CTB staining versus $1422 \pm 259$ GAP-43-positive axons at the same distance; a similar labeling ratio was seen at 1 $\mathrm{mm}$. The discrepancy between the numbers of CTB- and GAP43-positive axons may be attributable to a failure of RGCs distant from the injection site to take up CTB.

Although CNS myelin is inhibitory to axon growth, RGC axons appear to regenerate through myelin-rich areas of the nerve after lens puncture. This is apparent in double-immunostained sections in which we labeled growing axons with antibodies to GAP-43 and myelin with antibodies to MBP (Fig. $4 d-f$ ). Because the 15 $\mu \mathrm{m}$ sections are thicker than the axons, it remains possible that the axons may be growing through myelin-free zones within the nerve, although no gaps in the MBP staining pattern are apparent. The pattern of myelin staining in the nerve $21 \mathrm{~d}$ after crush has a reticulated appearance that differs from the continuous, striated staining found in the normal optic nerve (data not shown).

In the normal rat retina, GAP-43 immunostaining is limited to the processes of dopaminergic amacrine cells in the inner plexiform layer (Kapf hammer et al., 1997). RGCs are unstained (Fig. $5 a$ ), as are their axons within the optic nerve (Fig. 5b). Twenty one days after optic nerve crush without lens injury, RGCs remained unlabeled (Fig. 5c), although a few GAP-43-positive axons appeared in the optic nerve proximal to the crush site (Fig. $5 d$ ). Combining nerve crush with lens injury led to a dramatic increase in the immunostaining of RGCs and in their axons, as seen within the overlying fiber layer (Fig. 5e) and in the optic nerve proximal to the crush site $(5 f)$. The number of GAP-43positive fibers extending up to the injury site greatly exceeds the number that continues past this point (compare Fig. $2 a$ ). Surprisingly, even without nerve damage, lens injury stimulated RGCs to express GAP-43 across the full extent of the retina (Fig. $5 g$ ), despite the fact that the axons of these cells were not damaged. Correspondingly, some normal axons in the undamaged optic nerve showed GAP-43 immunostaining after lens injury (Fig. 5h).

GAP-43 was not detected in RGCs 24 hr after nerve crush with lens puncture (data not shown), but became visible by day 3 (Fig. $6 b$ ) and intensified by day 7 (Fig. $6 c$ ). By 21 d, GAP-43 levels were high throughout the retina (Fig. $6 d$ ). Animals with nerve crush alone showed only a small, transient increase in GAP-43 expression at $7 \mathrm{~d}$ (Fig. $7 a$ ) that could no longer be detected at $21 \mathrm{~d}$ (Fig. $7 b$ ). The effect of lens puncture alone on RGCs was evident on day 7 (Fig. $7 c$ ) and, as mentioned above, remained high at $21 \mathrm{~d}$ (Fig. $7 d$ ).

The effect of combining nerve injury and lens puncture is confirmed on western blots of the retina and proximal optic nerve segment (Fig. 8a,b). These studies were performed $14 \mathrm{~d}$ after surgery, a time at which the transient upregulation of GAP-43 expression from nerve injury alone has mostly subsided (Doster et al., 1991; Wodarczyk et al., 1997). Western blots showed little change in overall retinal GAP-43 levels $14 \mathrm{~d}$ after a nerve crush with a minimally invasive intraocular injection or after lens injury without nerve crush. This is presumably because the GAP-43 changes in RGCs induced by these manipulations are modest relative to the considerable and unchanging levels in amacrine cells. However, the effect of combining nerve crush and lens injury was clearly evident, both in the retina (Fig. $8 a$ ) and in the optic nerve (Fig. 8b), where the only source of GAP-43 is in RGC axons.

\section{Retinal ganglion cell survival}

To evaluate cell survival, we used Fluorogold to retrogradely label RGCs 1 week before surgery. In the normal, intact visual pathway, Fluorogold labeled numerous RGCs, which are characteristically round or oval cells, 12-15 $\mu \mathrm{m}$ across (Fig. 9a). Quantitation revealed a cell density of $1806 \pm 54 \mathrm{RGCs} / \mathrm{mm}^{2}(n=14$ cases; Fig. 9a,d), similar to previously reported results (Mey and Thanos, 1993; Mansour-Robaey et al., 1994; Clarke et al., 1998; Koeberle and Ball, 1998). Very few RGCs remained alive 3 

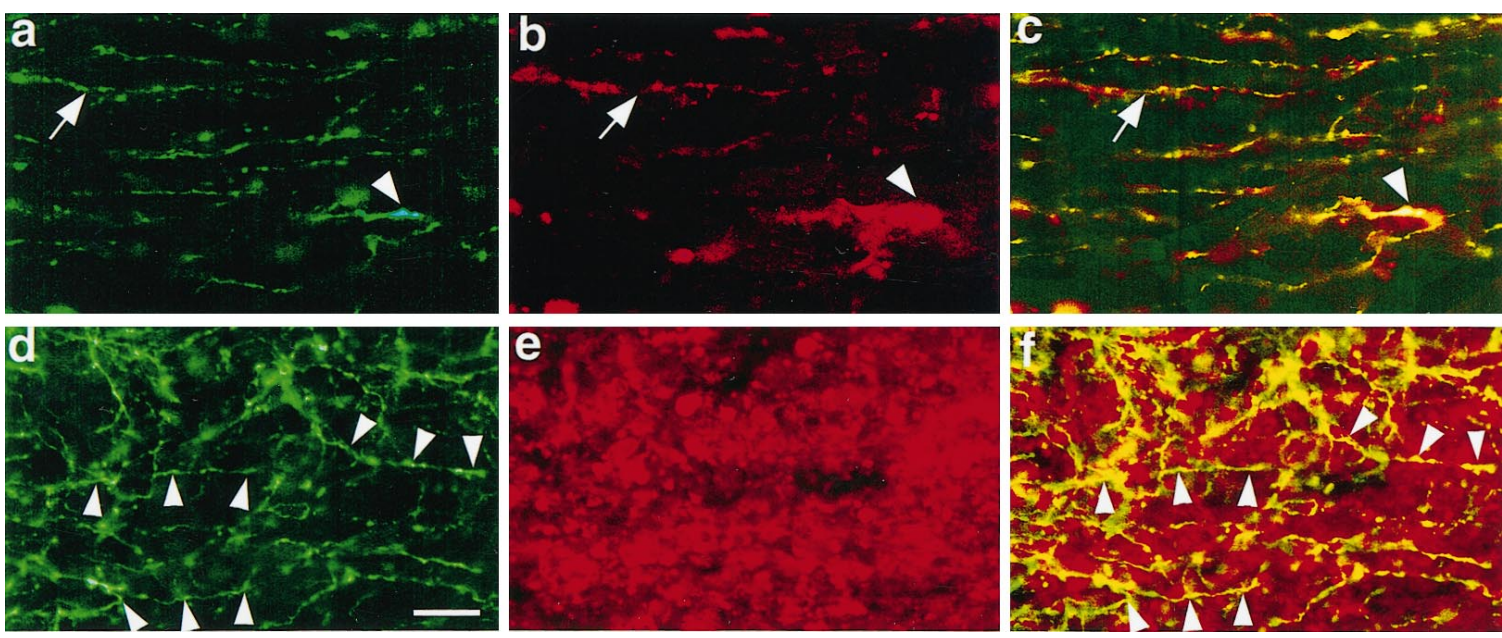

Figure 4. Double-labeling studies of regenerating axons. Double-immunofluorescent labeling shows that, after lens injury, the same axons (arrows) and presumed growth cone (arrowhead) are visualized distal to a crush site with an antibody to GAP-43 (a, arrows) and anti-CTB antibodies $(b)$; $c$, in the fusion of the two images, yellow reflects a superposition of the two labels. Scale bar, $100 \mu \mathrm{m}$. $d-f$, Double immunostaining for GAP-43 and myelin basic protein. After optic nerve crush plus lens puncture, numerous GAP-43-positive fibers (arrowheads) are seen distal to crush site in myelin-rich regions (e, immunostaining for myelin basic protein). $f$, Fusion of the two images. Scale bar, $100 \mu \mathrm{m}$.

weeks after nerve injury alone, or after nerve injury combined with a minimally invasive intraocular injection: in the latter case, we counted $59 \pm 21 \mathrm{RGCs} / \mathrm{mm}^{2}$, i.e., only $3 \%$ of the original number $(n=7)$. At the same time, numerous small, brightly fluorescent, spiny cells with multiple processes appeared (Fig. $9 b, e)$. These latter cells have been described previously in the injured retina and represent activated microglia (Thanos et al., 1993; Sawai et al., 1996; Clarke et al., 1998; Koeberle and Ball, 1998). When nerve injury was accompanied by lens puncture, RGC survival increased approximately eightfold, i.e., $24 \%$ of the original number of RGCs remained 3 weeks after surgery (430 \pm $\left.38 \mathrm{RGCs} / \mathrm{mm}^{2}: n=7\right)$. Microglia were still evident, but in much smaller numbers, and could be readily distinguished from RGCs by their morphology and location in a different optical plane (Fig. $9 c, f)$.

\section{Astrocyte reaction}

In normal rats, GFAP staining is restricted to the dense network of astrocytic processes in the innermost retina (Fig. 6e), and this did not change 7 or $21 \mathrm{~d}$ after nerve crush alone (Fig. 7e,f). Minimally invasive injections that did not infringe on the lens caused a local GFAP upregulation in the region of the needle track but not elsewhere (data not shown). However, puncturing the lens, even without injuring the nerve, stimulated GFAP expression in Müller cells across the full extent of the retina. This change was detectable by $3 \mathrm{~d}$, became pronounced by $7 \mathrm{~d}$ (Fig. $7 g$ ), and persisted for at least 3 weeks (Fig. 7h). Crushing the optic nerve in addition to puncturing the lens did not increase GFAP expression in Müller cells beyond the level induced by lens injury alone (Fig. $6 g, h$ ). These results are confirmed on western blots: lens puncture alone increased overall GFAP levels in the retina, whereas nerve crush alone had a smaller effect. The effect of combining nerve injury with lens puncture was similar to that of lens puncture alone (Fig. 8c).

\section{Macrophage reaction}

The normal retina does not contain ED-1-positive macrophages (Fig. 6i), and this was not altered by nerve crush alone (Fig. 7i,j) or by intraocular injections that did not infringe on the lens, except in the immediate vicinity of the needle track (data not shown). In contrast, lens injury led to widespread macrophage infiltration across the whole extent of the retina whether or not the nerve was crushed. This first became apparent at $3 \mathrm{~d}$ and intensified at $7 \mathrm{~d}$ (Fig. 7k); combining lens puncture with nerve injury induced about the same level of macrophage infiltration as lens puncture alone (Fig. $6 k$ ). Thus, the onset of the macrophage reaction correlates well with the changes seen in RGCs and in Müller cells: all three are induced strongly by lens injury but only minimally by nerve crush, and covary in time and space. Table 1 summarizes the pattern of changes seen in the eye 7-14 d after various experimental conditions. At 21 d, whereas GAP-43 expression in the retina and GFAP expression in Müller cells remained high (Figs. $6 d, h$ ), the number of ED-1-positive cells subsided considerably (Figs. 6l, $7 l$ ). As demonstrated by Fluorogold labeling, there are still numerous microglia in the retina at $21 \mathrm{~d}$, particularly after nerve crush alone (Fig. 9c,f), but these do not stain with the ED-1 antibody.

Immunizing animals against myelin has been reported to enable injured corticospinal tract axons to regenerate through the dorsal funiculus of the rat's spinal cord after injury (Huang et al., 1999). Because lens puncture causes a strong inflammatory reaction in the eye, we investigated whether it also stimulates an immune response that may contribute to RGC survival and axon regeneration. We obtained sera from normal controls or from animals having a nerve crush with a minimally invasive injection in the eye or nerve injury combined with lens puncture (all $7 \mathrm{~d}$ after surgery; $n=3$ in each group), and we used these sera to stain western blots of proteins from the retina and optic nerve (derived from normal animals and from animals $7 \mathrm{~d}$ after nerve crush). No differences were observed in the staining patterns obtained with the different antibodies (data not shown). It might also be predicted that if circulating antibodies were contributing to axon regeneration in our studies, lens puncture would help stimulate GAP-43 induction and axon regeneration in the contralateral optic nerve if it were also injured. Results from such studies show no GAP-43 changes in the retina or optic nerve contralateral to the eye receiving a lens puncture when both optic nerves were injured; only the side with the lens puncture exhibited elevated levels of GAP-43 (Fig. 8d). Similarly, immunohis- 

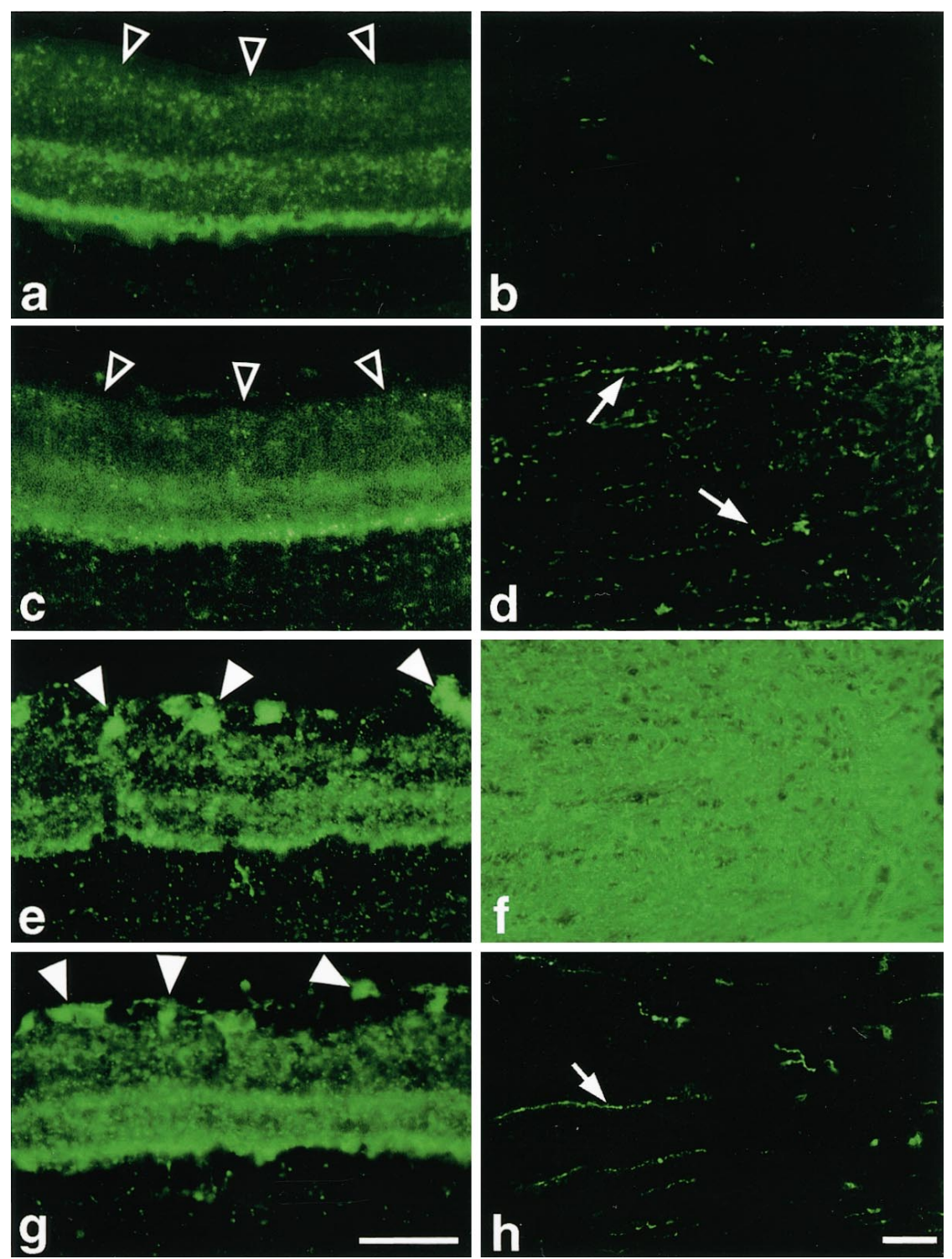

bands), but none in the ganglion cell layer (open arrows). Correspondingly, there is no axon staining in the normal optic nerve $(b)$. Twenty-one days after nerve crush alone, there is no change in the pattern of retinal staining $(c)$, although some positively stained axons appear in the optic nerve segment proximal to the crush site $(d$, arrows). After nerve crush accompanied by lens puncture, there is a marked increase in GAP-43 staining in RGCs (e, arrows) and in axons proximal to the injury site $(f)$. Lens puncture alone leads to a somewhat lesser increase in GAP-43 expression in RGCs $(g)$ and results in a small number of positively stained fibers in the optic nerve $(h$, arrow). Scale bar, $100 \mu \mathrm{m}$.

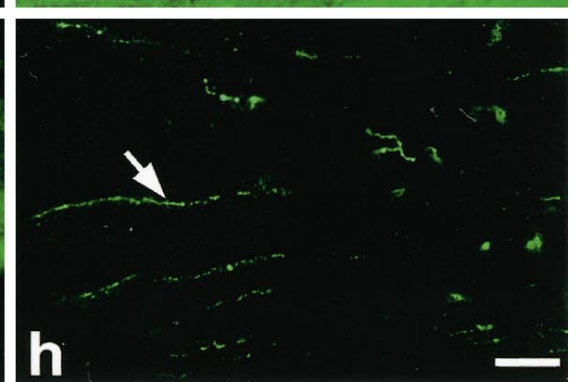

tochemistry revealed no axon growth past the injury site in an injured optic nerve when the contralateral lens was punctured (data not shown). These results suggest that GAP-43 induction and axon regeneration are related to local effects that ensue from lens puncture, rather than from systemically circulating agents, e.g., antibodies.

As described previously (Battisti et al., 1995), within the nerve, numerous macrophages were seen in the vicinity of the crush site within $7 \mathrm{~d}$ of injury, and by $14 \mathrm{~d}$, these cells became dispersed along the length of the nerve; by $21 \mathrm{~d}$, their distribution narrowed to the vicinity of the crush site. Puncturing the lens without crushing the nerve induced no macrophage reaction in the nerve, and combining lens puncture with nerve crush did not augment the response beyond the level seen after nerve crush alone (data not shown). By $7 \mathrm{~d}$, a massive cavity has formed at the crush site in all cases.

\section{Defined growth factors}

Puncture wounds to the posterior chamber of the eye cause a selective induction of CNTF and basic FGF mRNA (Faktorovich et al., 1992; Wen et al., 1995; Cao et al., 1997). CNTF induces
RGCs to extend axons in dissociated cell culture (Jo et al., 1999) and through a peripheral nerve graft in vivo (Cui et al., 1999). To investigate whether CNTF mediates the effects of lens puncture on RGCs, we injected CNTF into the vitreous at concentrations up to $1 \mu \mathrm{g} / \mathrm{ml}, \sim 1000$ times the $\mathrm{ED}_{50}$ required to stimulate rat RGCs in culture (Meyer-Franke et al., 1995; Jo et al., 1999). Axon growth was examined at $14 \mathrm{~d}$, a time point at which growth past the crush site becomes clear-cut after lens puncture, but before the effect of a single injection might have subsided. As summarized in Figure 10, intraocular injections of CNTF that did not infringe on the lens had no effect. We also investigated whether the RGC changes that result from lens puncture could be diminished with anti-CNTF antibodies (R \& D Systems; $20 \mu \mathrm{g} / \mathrm{ml}$, a quantity sufficient to neutralize $80 \%$ of the activity of $1 \mathrm{ng} / \mathrm{ml}$ of CNTF). No changes were observed (Fig. 10). Neutralizing antibodies to BDNF or basic FGF likewise failed to diminish the number of axons measured at 0.5 or $1 \mathrm{~mm}$ distal to the injury site after lens puncture (Fig. 10). However, anti-BDNF antibody treatment doubled the length of the longest regenerating axon measured distal to the injury site (for nerve crush plus lens 


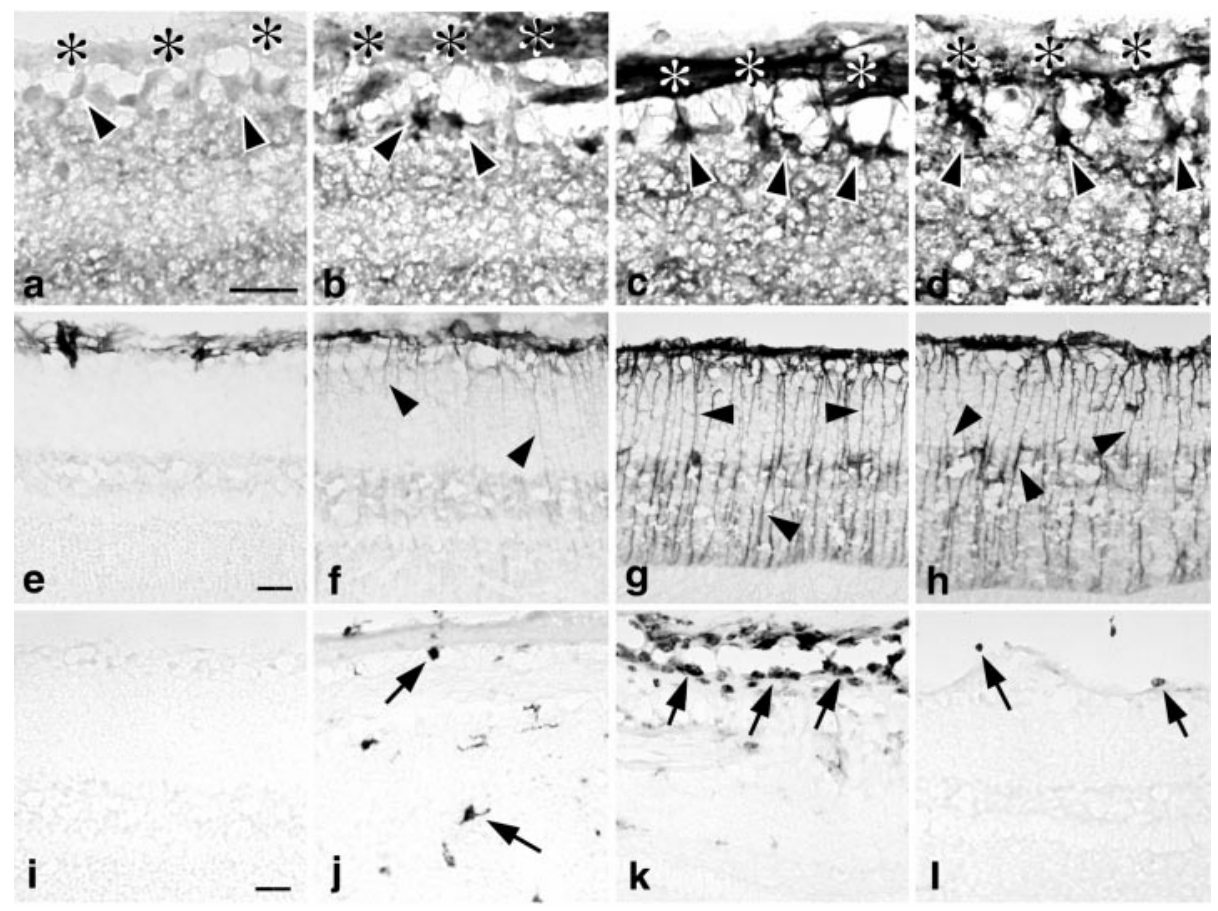

Figure 6. Time course of GAP-43, GFAP, and ED1 immunostaining in the retina after nerve crush combined with lens puncture. $a-d$, GAP-43 immunostaining in RGCs in the normal retina (a) and at 3-21 d after surgery. Three days after nerve crush with lens puncture, RGCs begin to show increased GAP-43 levels in their somata $(b$, arrows) and in their axons in the overlying optic fiber layer (asterisks); staining intensifies by day 7 (c) and remains high at day $21(d) . e, h$, Mueller cells show a parallel activation, as indicated by increased GFAP staining on day $3(f)$, which intensifies further on days 7-21 $(g, h) . i-l$, Monocyte activation in the retina is visualized by ED1 staining. Whereas most of the ED-1-positive cells seen at day $3(j)$ are within the retinal neuropil, by day 7 , most appear on the surface of the retina (k); the number of ED-1-positive cells decreases by day $21(l)$. Scale bar, $100 \mu \mathrm{m}$. puncture, average $\pm \mathrm{SEM}=2.71 \pm 0.52 \mathrm{~mm}$; for similarly treated animals with anti-BDNF injections, longest axon $=5.65 \pm 0.61$ $\mathrm{mm} ; t=3.67 ; p<0.01 ; \mathrm{df}=8)$. No other treatment significantly altered axon length.

\section{Multiple punctures}

We investigated whether the regenerative changes obtained after a single lens injury could be augmented by multiple punctures. This was examined by making either 10 punctures on the same day as the nerve injury or five punctures at $3 \mathrm{~d}$ intervals beginning the same day as the nerve crush. Both of these treatments only diminished axon growth, perhaps because of generalized trauma to the retina. Thus, a single, spatially restricted lens puncture appears to elicit a maximal response in RGCs.

\section{Macrophage activation mimics the effect of lens puncture}

To determine whether macrophages mediate the effect of lens puncture on RGC survival and axon regeneration, we used several methods to activate macrophages without encroaching on the

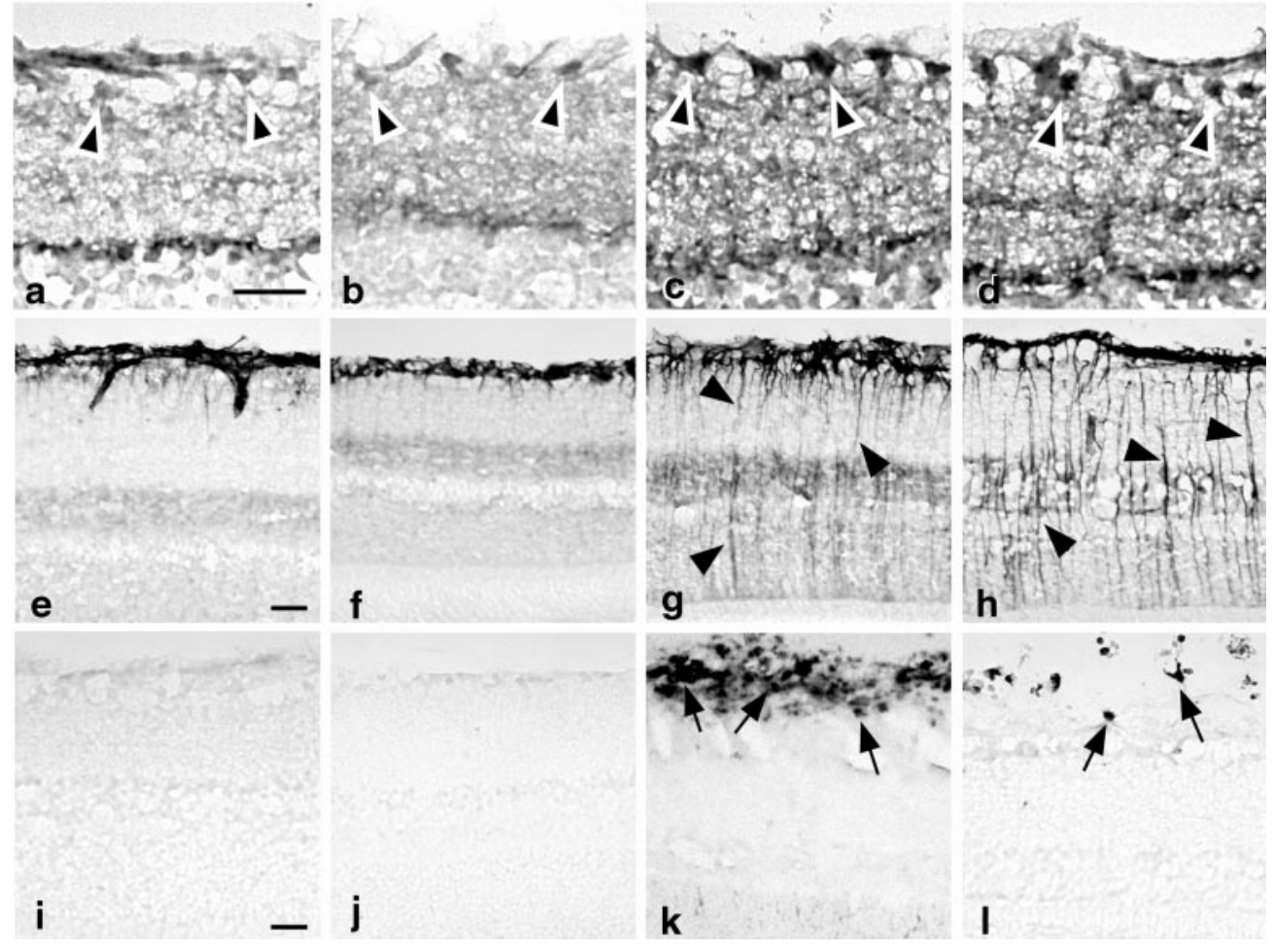

Figure 7. Effects of lens puncture or nerve injury alone. Nerve crush alone stimulates only a small change in GAP-43 expression in RGCs on day 7 $(a)$ or day $21(b)$ after surgery. In parallel to this, there is no change of GFAP expression in Müller cells $(e, f)$ or in the number of ED-1-positive macrophages $(i, j)$. In contrast, lens puncture alone induces changes in all three cell types by day $7(c, g, k)$. The changes in RGCs $(d)$ and Müller cells $(h)$ remain high at day 21, although ED1 staining reveals fewer macrophages at this time point. Scale bar, $100 \mu \mathrm{m}$. 


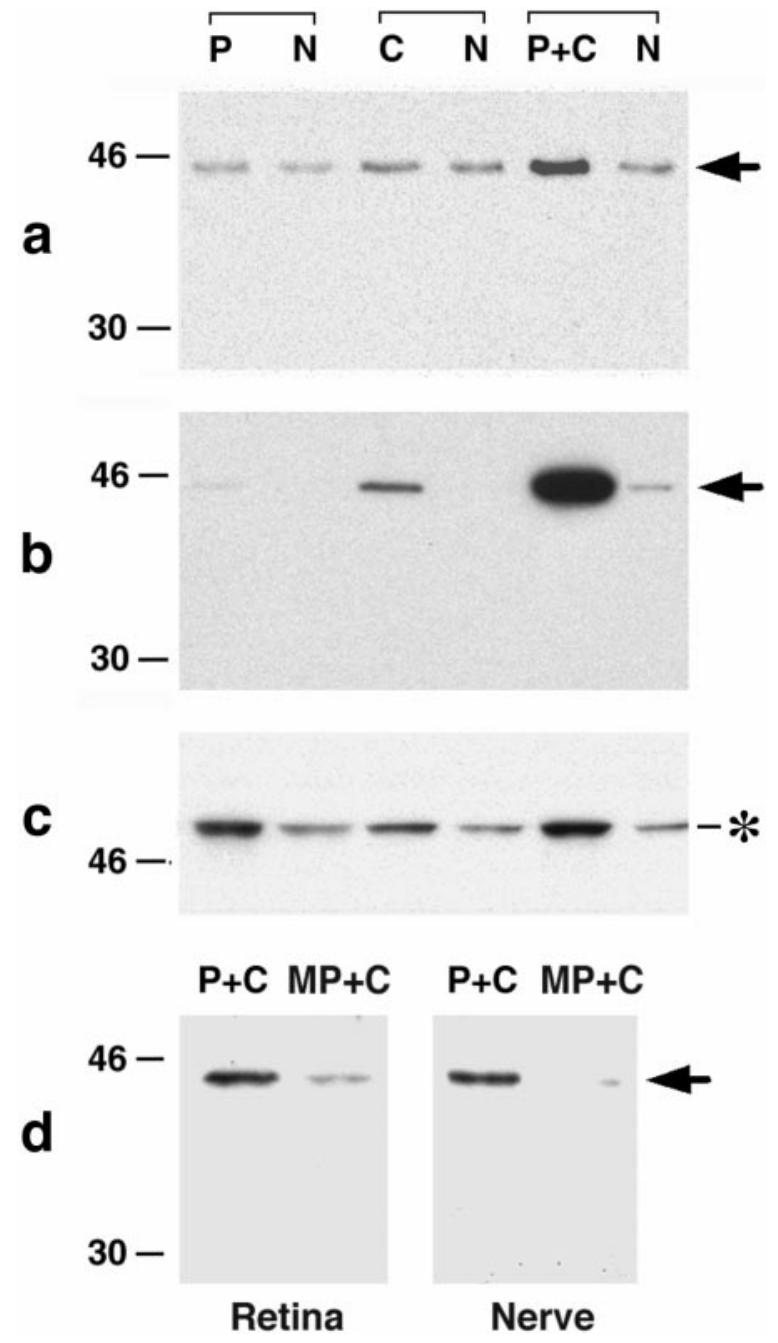

Figure 8. Changes in GAP-43 and GFAP expression: Western blots. Lens puncture combined with nerve crush $(P+C)$ results in increased GAP-43 levels in the retina ( $a$, arrow), and even more strikingly, in the proximal portion of the optic nerve ( $b$, arrow; $N$ represents the normal, contralateral side of the experimental animal; all results are at $14 \mathrm{~d}$ after surgery). $c$, GFAP levels are upregulated equally by lens puncture alone $(P)$ or lens puncture plus nerve crush $(P+C)$. Nerve crush alone $(C)$ causes a lesser change. $d$, A case in which both optic nerves were crushed but the lens was injured on only one side. There is a much greater increase in GAP-43 in the retina and optic nerve on the side with lens puncture plus nerve crush $(P+C)$ than on the contralateral side having a minimally invasive intraocular puncture that does not infringe on the lens $(M P+C)$.

lens. Of these, the greatest effect was achieved using Zymosan, a yeast cell wall suspension, to augment the modest macrophage response that occurs after minimally invasive intraocular injections. Zymosan stimulated an extensive macrophage response in the eye (Fig. 11a), and this was paralleled by an upregulation of GFAP in Müller cells (Fig. 11b) and of GAP-43 in RGCs (Fig. $11 c$ ); under these conditions, we observed extensive axon regeneration past the site of nerve injury (Fig. 11d). Consistent results were seen in all five Zymosan-treated cases.

The vitreous is highly inhibitory to inflammation (Osusky et al., 1996); in conformity with this, we were unable to elicit a sustained macrophage reaction by injecting IFN- $\gamma$ or by introducing activated peritoneal macrophages. Correlated with the absence of monocyte activation were an absence of GAP-43 upregulation in RGCs and a failure of axons to regenerate past the crush site in the nerve. IFN- $\gamma$ did, however, stimulate GFAP expression in Müller cells (data not shown). None of the inhibitors used (MIF, Ciglitazone, prostaglandin J2) diminished macrophage activation after lens puncture, nor did they alter GAP-43 expression.

\section{DISCUSSION}

In mature mammals, RGCs are unable to regrow injured axons and soon undergo apoptotic death (Garcia-Valenzuela et al., 1994). These well known events are a paradigm of regenerative failure in the CNS and may mimic pathophysiological sequelae that underlie degenerative diseases such as glaucoma (Quigley and Green, 1979; Quigley et al., 1995). However, as shown here, if the lens is injured, RGCs show increased survival and regenerate their axons into the distal optic nerve.

The pro-regenerative effects of lens puncture appear to be mediated through activated macrophages. Within $3 \mathrm{~d}$ of nerve crush with lens puncture, ED-1-positive monocytes appear across the entire retina. This is paralleled by an upregulation of GAP-43 in RGCs and of GFAP in Müller cells; these changes all intensify by $7 \mathrm{~d}$ and remain high for another week. Macrophage activity then begins to decline, but the changes in Müller cells and RGCs persist. In the absence of lens puncture, nerve injury, either alone or combined with a minimally invasive intraocular injection, induces only minor macrophage activation, and is soon followed by massive RGC death. To investigate whether macrophages play a causative role in stimulating RGC survival and regeneration, we used several methods to stimulate monocytes without infringing on the lens. Zymosan, a yeast membrane suspension that activates the mannose and $\beta$-glucan lectin-binding site of the CR3 $\beta_{2}$ integrin receptors (Lombard et al., 1994; Xia et al., 1999), resulted in massive macrophage infiltration into the eye. This was accompanied by a dramatic increase in GAP-43 expression in RGCs and axon regeneration beyond the injury site.

The vitreous is normally suppressive to inflammation; this has been attributed to high levels of hyaluronic acid and TGF- $\beta$ II (Osusky et al., 1996). In conformity with this, we were unable to stimulate macrophages with IFN- $\gamma$, and peritoneal macrophages did not remain activated in a host vitreous without lens puncture. Thus, lens puncture may release agents that overcome the antiinflammatory influences that normally prevail intravitreally, e.g., $\alpha$-crystallin (Bhat and Sharma, 1999). Huang et al. (1999) have reported that immunizing rats to myelin stimulates the formation of antibodies that enable corticospinal tract axons to regenerate after spinal cord injury. However, our results indicate that the effects of lens puncture and macrophage activation are local and are not mediated through circulating antibodies.

The factors that mediate the effects of monocyte activation on RGCs are as yet unknown. Activated monocytes release a host of cytokines and growth factors that can affect neurons directly or via glial stimulation (Giulian, 1993; Kreutzberg, 1996). In the rat striatum, puncture wounds stimulate microglia that express BDNF and promote the infiltration of macrophages that express GDNF; these two growth factors are likely to contribute to the survival and outgrowth of dopaminergic neurons that occurs after puncture wounds (Batchelor et al., 1999). BDNF and GDNF also affect RGC survival after axotomy (Mey and Thanos, 1993; Mansour-Robaey et al., 1994; Sawai et al., 1996; Di Polo et al., 1998; Koeberle and Ball, 1998) and could play a role here. However, neutralizing anti-BDNF antibodies did not diminish the positive effects of lens injury, but augmented the length of axon growth into the distal optic nerve. This unanticipated effect on axon length may be a consequence of suppressing the effects of 

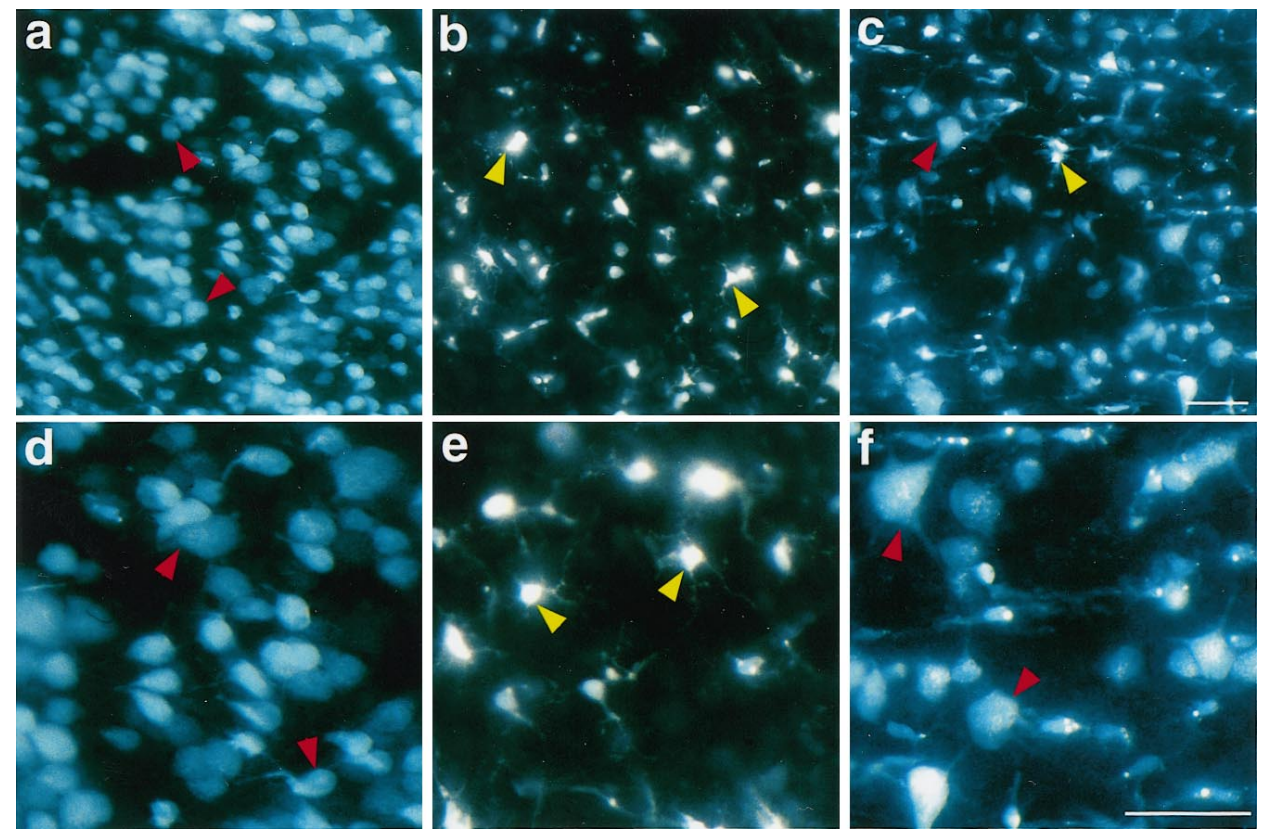

Figure 9. Lens puncture enhances RGC survival. RGC survival was evaluated using Fluorogold to retrogradely label RGCs 1 week before surgery. In the normal retina, RGCs appear as oval cells with a pale bluewhite fluorescence $(a, d$, red arrows). Optic nerve crush, either alone or with a minimally invasive injection $(b, e)$, results in the death of most RGCs by day 21. Activated microglia pick up label by phagocytosis, and are readily distinguished from RGCs by virtue of their brilliant white fluorescence and multiple, thin processes (green arrows). Nerve crush combined with lens puncture increases RGC survival (c, $f$, red arrows) and decreases the number of microglia in the retina. Scale bar, $100 \mu \mathrm{m}$.
BDNF on axon branching (Mansour-Robaey et al., 1994; Sawai et al., 1996; Cohen-Cory, 1999; Jo et al., 1999; Lom and CohenCory, 1999). In terms of glial contributions, activated Müller cells increase CNTF expression (Ju et al., 1999), and CNTF can stimulate RGC survival (Mey and Thanos, 1993; Meyer-Franke et al., 1995) and axon regeneration (Cui et al., 1999; Jo et al., 1999). However, intraocular injections of CNTF did not stimulate axon regeneration in the absence of lens puncture, and anti-CNTF antibodies did not diminish the effects of lens injury. Traumatic injury to the eye also increases mRNA for bFGF (Faktorovich et al., 1992; Wen et al., 1995; Cao et al., 1997), but again, anti-bFGF antibodies did not diminish the effect of lens puncture. These results cannot be interpreted too literally, however, because the diffusion and degradation of the growth factors and antibodies may render their concentrations too low to be effective. A number of studies on trophic factors in the eye found that control injections enhanced RGC survival (Mansour-Robaey et al., 1994; Koeberle and Ball, 1998). These effects may have resulted in part from inadvertent lens injury, because in our hands, intraocular injections that did not infringe on the lens had little effect on RGCs.

Peripheral nerve fragments implanted into the vitreous stimulate RGCs to regenerate their axons into the optic nerve, particularly when the implant is derived from a peripheral nerve that had first been injured and allowed to degenerate in vivo for several days (Berry et al., 1996). Peripheral nerve injury stimulates considerable macrophage infiltration (Berry et al., 1996) and, as shown here, the latter cells may have contributed to the observed regenerative response. In support of this, a predegenerated peripheral nerve epineurium without Schwann cells stimulates RGCs to sprout processes in the retina and to upregulate GAP-43 expression, again suggesting a role for macrophages (Lai and Cho, 1999).

Although our results indicate that activated monocytes promote RGC survival and outgrowth, they are also likely to exert adverse effects. Developmentally, microglia play a role in eliminating supernumerary RGCs by secreting NGF; RGCs lack trkA receptors, and NGF acting on the low-affinity p75NTR receptors of these cells leads to cell death (Frade et al., 1996; Frade and Barde, 1998). This may also occur in the axotomized adult retina, but can be counteracted by other growth factors released by macrophages. In addition, activated monocytes can exert negative effects through nitric oxide, oxygen-free radicals, arachidonic acid derivatives, proteases, excitatory amino acids, quinolinic acid, and other cytokines (Giulian et al., 1993, 1994; Kreutzberg, 1996). Intravitreal injections of a tripeptide MIF have been reported to increase RGC survival (Thanos et al., 1993; Moore and Thanos, 1996), although in our hands, MIF had little effect on monocyte activity or RGC survival. In the optic nerve, macrophages may help transform the nonpermissive adult optic nerve into a permissive substrate for neurite growth by phagocytosing inhibitory cellular debris (David et al., 1990; Lazarov-Spiegler et al., 1996, 1998; Schafer et al., 1996). However, the macrophage reaction in the optic nerve is clearly insufficient to promote RGC survival or axon growth.

One factor that still places severe limits on axon regeneration is the glial scar (Reier et al., 1983; Rudge and Silver, 1990; McKeon et al., 1991; Fitch et al., 1999). After lens puncture and nerve crush, most RGCs appear to be "growth-enabled", as suggested by the high levels of GAP-43 in their somata and proximal axon

Table 1. Summary of changes resulting from nerve injury and/or lens puncture

\begin{tabular}{lllll} 
Cellular change & Control & Nerve crush & Lens puncture & Crush + puncture \\
\hline GAP-43 $^{+}$RGCs & - & $+/-$ & ++ & +++ \\
$\mathrm{GFAP}^{+}$Müller cells & - & $+/-$ & ++ & ++ \\
$\mathrm{ED}^{+}$macrophages & - & - & +++ & +++ \\
\hline
\end{tabular}




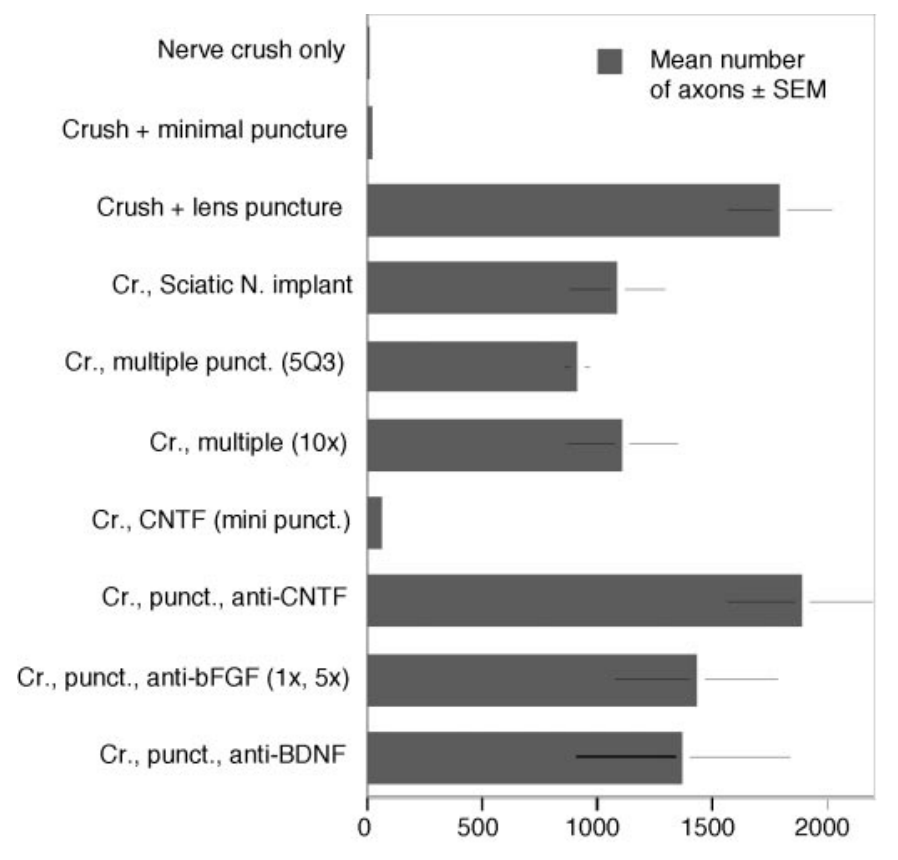

Axons at $0.5 \mathrm{~mm}$

Figure 10. Quantitation of axon growth after various treatments. The combination of nerve crush plus lens puncture induces nearly 2000 axons to regenerate $>500 \mu \mathrm{m}$ past the injury site. This represents a 100 -fold increase relative to animals with nerve crush only. Multiple punctures (Cr., multiple punct.) or an intravitreal sciatic nerve implant (Cr., Sciatic N. implant) stimulate significantly less growth. Intravitreal injections of CNTF without lens injury (Cr., CNTF mini punct.) do not mimic the effects of lens puncture, and anti-CNTF antibodies do not decrease axon growth in lens-puncture cases (Cr., punct., anti-CNTF). Antibodies to BDNF or bFGF also fail to diminish axon growth after lens puncture $(C r$., punct., anti-BDNF; Cr., punct., anti-bFGF).

segments. However, of the surviving RGCs, $<10 \%$ extend an axon beyond the crush site. Thus, although lens puncture makes surviving RGCs competent to regenerate their axons, the scar prevents these axons from growing further.

Myelin also normally represents a major impediment to axon growth in the CNS (Caroni et al., 1988; Schwab and Caroni, 1988; Shewan et al., 1995). However, as shown here and elsewhere, mature RGCs can extend lengthy axons into the myelinated optic nerve when appropriately stimulated. Other studies have shown more restricted axon growth in the mature optic nerve after intravitreal injections of angiotensin II (Lucius et al., 1998) or by inactivating the GTPase Rho, (Lehmann et al., 1999).

A surprising effect of lens puncture was to induce RGCs to express GAP-43 even when not growing axons. Developmentally, RGCs express this protein during axon outgrowth and synaptic refinement, then downregulate it as their connections mature (Skene and Willard, 1981b; Meiri et al., 1986; Moya et al., 1988). Normally, GAP-43 is transiently upregulated after axotomy and declines as RGCs undergo atrophic changes (Doster et al., 1991; Fournier et al., 1997; Wodarczyk et al., 1997; Wouters et al., 1998). Levels remain high only if regeneration is sustained (Skene and Willard, 1981a; Benowitz and Lewis, 1983; Doster et al., 1991; Meyer et al., 1994; Schaden et al., 1994; Berry et al., 1996). In the present study, lens puncture and nerve injury had independent and synergistic effects on GAP-43 expression. Whereas axotomy alone induced only a weak and transient response, the effect of lens puncture persisted for at least 3 weeks, and the two

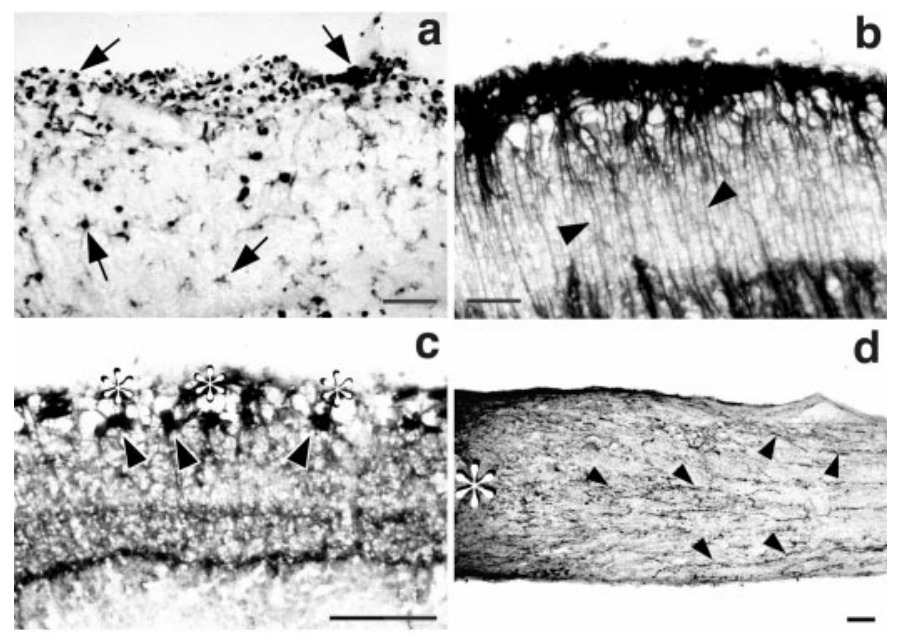

Figure 11. Macrophage activation mimics the effect of lens puncture. $a$, A single injection of Zymosan into the vitreous results in a massive infiltration of ED-1-positive monocytes in the retina (arrows). This is paralleled by increased GFAP expression in Müller cells ( $b$, arrowheads), increased GAP-43 levels in RGCs (c, arrowheads) and in their axons in the overlying fiber layer (asterisks), and growth of GAP-43-positive axons past the injury site ( $d$,asterisk) into the distal portion of the optic nerve (arrowheads).

combined resulted in an induction that was considerably more than additive.

In mice that overexpress the anti-apoptotic protein $\mathrm{Bcl}-2$, RGCs survive axotomy but do not regenerate their axons (Chierzi et al., 1999). Thus, axon growth is not a simple consequence of enhancing cell survival. It would appear that some factor released by activated macrophages activates the growth program in RGCs over and above of any changes in cell survival.

\section{REFERENCES}

Aguayo AJ, Vidal-Sanz M, Villegas-Perez MP, Bray GM (1987) Growth and connectivity of axotomized retinal neurons in adult rats with optic nerves substituted by PNS grafts linking the eye and the midbrain. Ann NY Acad Sci 495:1-9.

Battisti WP, Wang J, Bozek K, Murray M (1995) Macrophages, microglia, and astrocytes are rapidly activated after crush injury of the goldfish optic nerve: a light and electron microscopic analysis. J Comp Neurol 354:306-320.

Batchelor PE, Liberatore GT, Wong JY, Porritt MJ, Frerichs F, Donnan GA, Howells DW (1999) Activated macrophages and microglia induce dopaminergic sprouting in the injured striatum and express brainderived neurotrophic factor and glial cell line-derived neurotrophic factor. J Neurosci 19:1708-1716.

Benowitz LI, Lewis ER (1983) Increased transport of 44,000- to 49,000dalton acidic proteins during regeneration of the goldfish optic nerve: a two-dimensional gel analysis. J Neurosci 3:2153-2163.

Benowitz LI, Apostolides PJ, Perrone-Bizzozero N, Finklestein SP, Zwiers H (1988) Anatomical distribution of the growth-associated protein GAP-43/B-50 in the adult rat brain. J Neurosci 8:339-352.

Berkelaar M, Clarke DB, Wang YC, Bray GM, Aguayo AJ (1994) Axotomy results in delayed death and apoptosis of retinal ganglion cells in adult rats. J Neurosci 14:4368-4374.

Berry M, Carlile J, Hunter A (1996) Peripheral nerve explants grafted into the vitreous body of the eye promote the regeneration of retinal ganglion cell axons severed in the optic nerve. J Neurocytol 25:147-170.

Bhat NR, Sharma KK (1999) Microglial activation by the small heat shock protein, alpha-crystallin. NeuroReport 10:2869-2873.

Bonfanti L, Strettoi E, Chierzi S, Cenni MC, Liu XH, Martinou JC, Maffei L, Rabacchi SA (1996) Protection of retinal ganglion cells from natural and axotomy-induced cell death in neonatal transgenic mice overexpressing bcl-2. J Neurosci 16:4186-4194.

Bray GM, Villegas-Perez MP, Vidal-Sanz M, Aguayo AJ (1987) The use of peripheral nerve grafts to enhance neuronal survival, promote 
growth and permit terminal reconnections in the central nervous system of adult rats. J Exp Biol 132:5-19.

Cao W, Wen R, Li F, Lavail MM, Steinberg RH (1997) Mechanical injury increases bFGF and CNTF mRNA expression in the mouse retina. Exp Eye Res 65:241-248.

Carmignoto G, Maffei L, Candeo P, Canella R, Comelli C (1989) Effect of NGF on the survival of rat retinal ganglion cells following optic nerve section. J Neurosci 9:1263-1272.

Caroni P, Savio T, Schwab ME (1988) Central nervous system regeneration: oligodendrocytes and myelin as non-permissive substrates for neurite growth. Prog Brain Res 78:363-370.

Chierzi S, Strettoi E, Cenni MC, Maffei L (1999) Optic nerve crush: axonal responses in wild-type and bcl-2 transgenic mice. J Neurosci 19:8367-8376.

Clarke DB, Bray GM, Aguayo AJ (1998) Prolonged administration of NT-4/5 fails to rescue most axotomized retinal ganglion cells in adult rats. Vision Res 38:1517-1524.

Cohen A, Bray GM, Aguayo AJ (1994) Neurotrophin-4/5 (NT-4/5) increases adult rat retinal ganglion cell survival and neurite outgrowth in vitro. J Neurobiol 25:953-959.

Cohen-Cory S (1999) BDNF modulates, but does not mediate, activitydependent branching and remodeling of optic axon arbors in vivo. J Neurosci 19:9996-10003.

Cui Q, Lu Q, So KF, Yip HK (1999) CNTF, not other trophic factors, promotes axonal regeneration of axotomized retinal ganglion cells in adult hamsters. Invest Ophthalmol Vis Sci 40:760-766.

David S, Bouchard C, Tsatas O, Giftochristos N (1990) Macrophages can modify the nonpermissive nature of the adult mammalian central nervous system. Neuron 5:463-469.

Di Polo A, Aigner LJ, Dunn RJ, Bray GM, Aguayo AJ (1998) Prolonged delivery of brain-derived neurotrophic factor by adenovirusinfected Muller cells temporarily rescues injured retinal ganglion cells. Proc Natl Acad Sci USA 95:3978-3983.

Doster SK, Lozano AM, Aguayo AJ, Willard MB (1991) Expression of the growth-associated protein GAP-43 in adult rat retinal ganglion cells following axon injury. Neuron 6:635-647.

Faktorovich EG, Steinberg RH, Yasumura D, Matthes MT, LaVail MM (1992) Basic fibroblast growth factor and local injury protect photoreceptors from light damage in the rat. J Neurosci 12:3554-3567.

Fitch MT, Doller C, Combs CK, Landreth GE, Silver J (1999) Cellular and molecular mechanisms of glial scarring and progressive cavitation: in vivo and in vitro analysis of inflammation-induced secondary injury after CNS trauma. J Neurosci 19:8182-8198.

Fournier AE, Beer J, Arregui CO, Essagian C, Aguayo AJ, McKerracher L (1997) Brain-derived neurotrophic factor modulates GAP-43 but not $\mathrm{T}$ alpha1 expression in injured retinal ganglion cells of adult rats. J Neurosci Res 47:561-572.

Frade JM, Barde YA (1998) Microglia-derived nerve growth factor causes cell death in the developing retina. Neuron 20:35-41.

Frade JM, Rodriguez-Tebar A, Barde YA (1996) Induction of cell death by endogenous nerve growth factor through its p75 receptor. Nature 383:166-168.

Garcia-Valenzuela E, Gorczyca W, Darzynkiewicz Z, Sharma SC (1994) Apoptosis in adult retinal ganglion cells after axotomy. J Neurobiol 25:431-438.

Giulian D (1993) Reactive glia as rivals in regulating neuronal survival. Glia 7:102-110.

Giulian D, Vaca K, Corpuz M (1993) Brain glia release factors with opposing actions upon neuronal survival. J Neurosci 13:29-37.

Giulian D, Li J, Leara B, Keenen C (1994) Phagocytic microglia release cytokines and cytotoxins that regulate the survival of astrocytes and neurons in culture. Neurochem Int 25:227-233.

Huang DW, McKerracher L, Braun PE, David S (1999) A therapeutic vaccine approach to stimulate axon regeneration in the adult mammalian spinal cord. Neuron 24:639-647.

Jo S, Wang E, Benowitz LI (1999) CNTF is an endogenous axon regeneration factor for mammalian retinal ganglion cells. Neuroscience 89:579-591.

Ju WK, Lee MY, Hofmann HD, Kirsch M, Chun MH (1999) Expression of CNTF in Muller cells of the rat retina after pressure-induced ischemia. NeuroReport 10:419-422.

Kapfhammer JP, Christ F, Schwab ME (1997) The growth-associated protein GAP-43 is specifically expressed in tyrosine hydroxylasepositive cells of the rat retina. Dev Brain Res 101:257-264.

Kermer P, Klocker N, Labes M, Bahr M (1998) Inhibition of CPP32-like proteases rescues axotomized retinal ganglion cells from secondary cell death in vivo. J Neurosci 18:4656-4662.

Koeberle PD, Ball AK (1998) Effects of GDNF on retinal ganglion cell survival following axotomy. Vision Res 38:1505-1515.

Kreutzberg GW (1996) Microglia: a sensor for pathological events in the CNS. Trends Neurosci 19:312-318.

Lai MY, Cho EYP (1999) Regenerative sprouting of retinal ganglion cells of adult hamsters induced by the epineurium of a peripheral nerve. Brain Res 823:241-248.

Lazarov-Spiegler O, Solomon AS, Schwartz M (1998) Peripheral nervestimulated macrophages simulate a peripheral nerve-like regenerative response in rat transected optic nerve. Glia 24:329-337.

Lazarov-Spiegler O, Solomon AS, Zeev-Brann AB, Hirschberg DL, Lavie V, Schwartz M (1996) Transplantation of activated macrophages overcomes central nervous system regrowth failure. FASEB J 10:1296-1302.

Lehmann M, Fournier A, Selles-Navarro I, Dergham P, Sebok A, Leclerc N, Tigyi G, McKerracher L (1999) Inactivation of rho signaling pathway promotes CNS axon regeneration. J Neurosci 19:7537-7547.

Lom B, Cohen-Cory S (1999) Brain-derived neurotrophic factor differentially regulates retinal ganglion cell dendritic and axonal arborization in vivo. J Neurosci 19:9928-9938.

Lombard Y, Giaimis J, Makaya-Kumba M, Fonteneau P, Poindron P (1994) A new method for studying the binding and ingestion of zymosan particles by macrophages. J Immunol Meth 174:155-165.

Lucius R, Gallinat S, Rosenstiel P, Herdegen T, Sievers J, Unger T (1998) The angiotensin II type 2 (AT2) receptor promotes axonal regeneration in the optic nerve of adult rats. J Exp Med 188:661-670.

Mansour-Robaey S, Clarke DB, Wang YC, Bray GM, Aguayo AJ (1994) Effects of ocular injury and administration of brain-derived neurotrophic factor on survival and regrowth of axotomized retinal ganglion cells. Proc Natl Acad Sci USA 91:1632-1636.

McKeon RJ, Schreiber RC, Rudge JS, Silver J (1991) Reduction of neurite outgrowth in a model of glial scarring following CNS injury is correlated with the expression of inhibitory molecules on reactive astrocytes. J Neurosci 11:3398-3411.

Meiri KF, Pfenninger KH, Willard MB (1986) Growth-associated protein, GAP-43, a polypeptide that is induced when neurons extend axons, is a component of growth cones and corresponds to pp46, a major polypeptide of a subcellular fraction enriched in growth cones. Proc Natl Acad Sci USA 83:3537-3541.

Mey J, Thanos S (1993) Intravitreal injections of neurotrophic factors support the survival of axotomized retinal ganglion cells in adult rats in vivo. Brain Res 602:304-317.

Meyer RL, Miotke JA, Benowitz LI (1994) Injury induced expression of growth-associated protein- 43 in adult mouse retinal ganglion cells in vitro. Neuroscience 63:591-602.

Meyer-Franke A, Kaplan MR, Pfrieger FW, Barres BA (1995) Characterization of the signaling interactions that promote the survival and growth of developing retinal ganglion cells in culture. Neuron 15:805-819.

Meyer-Franke A, Wilkinson GA, Kruttgen A, Hu M, Munro E, Hanson Jr MG, Reichardt LF, Barres BA (1998) Depolarization and cAMP elevation rapidly recruit TrkB to the plasma membrane of CNS neurons. Neuron 21:681-693.

Moore S, Thanos S (1996) The concept of microglia in relation to central nervous system disease and regeneration. Prog Neurobiol 48:441-460.

Moya KL, Benowitz LI, Jhaveri S, Schneider GE (1988) Changes in rapidly transported proteins in developing hamster retinofugal axons. J Neurosci 8:4445-4454.

O'Farrell PH (1975) High resolution two-dimensional electrophoresis of proteins. J Biol Chem 250:4007-4021.

Osusky R, Walker SM, Ryan SJ (1996) Vitreous body affects activation and maturation of monocytes into macrophages. Graefes Arch Clin Exp Ophthalmol 234:637-642.

Quigley HA, Green WR (1979) The histology of human glaucoma cupping and optic nerve damage: clinicopathologic correlation in 21 eyes. Ophthalmology 86:1803-1830.

Quigley HA, Nickells RW, Kerrigan LA, Pease ME, Thibault DJ, Zack DJ (1995) Retinal ganglion cell death in experimental glaucoma and after axotomy occurs by apoptosis. Invest Ophthalmol Vis Sci 36:774-786.

Rabacchi SA, Ensini M, Bonfanti L, Gravina A, Maffei L (1994) Nerve growth factor reduces apoptosis of axotomized retinal ganglion cells in the neonatal rat. Neuroscience 63:969-973. 
Ramon y Cajal S (1991) Degeneration and regeneration of the nervous system, Vol 5 (Jones JD, Jones EG, eds). New York: Oxford UP.

Reier PJ, Stensaas LJ, Guth L (1983) The astrocytic scar as an impediment to regeneration in the central nervous system. In: Spinal cord reconstruction (Kao CC, Bunge RP, Reier PJ, eds), pp 163-195. New York: Raven.

Ross GD, Vetvicka V (1993) CR3 (CD11b, CD18): a phagocyte and NK cell membrane receptor with multiple ligand specificities and functions. Clin Exp Immunol 92:181-184.

Rudge JS, Silver J (1990) Inhibition of neurite outgrowth on astroglial scars in vitro. J Neurosci 10:3594-3603.

Sawai H, Clarke DB, Kittlerova P, Bray GM, Aguayo AJ (1996) Brainderived neurotrophic factor and neurotrophin- $4 / 5$ stimulate growth of axonal branches from regenerating retinal ganglion cells. J Neurosci 16:3887-3894.

Schaden H, Stuermer CA, Bahr M (1994) GAP-43 immunoreactivity and axon regeneration in retinal ganglion cells of the rat. J Neurobiol 25:1570-1578.

Schafer M, Fruttiger M, Montag D, Schachner M, Martini R (1996) Disruption of the gene for the myelin-associated glycoprotein improves axonal regrowth along myelin in C57BL/Wlds mice. Neuron 16:1107-1113.

Schwab ME, Caroni P (1988) Oligodendrocytes and CNS myelin are nonpermissive substrates for neurite growth and fibroblast spreading in vitro. J Neurosci 8:2381-2393.

Sethna MP, Lampson LA (1991) Immune modulation within the brain: recruitment of inflammatory cells and increased major histocompatibility antigen expression following intracerebral injection of interferongamma. J Neuroimmunol 34:121-132.

Shen S, Wiemelt AP, McMorris FA, Barres BA (1999) Retinal ganglion cells lose trophic responsiveness after axotomy. Neuron 23:285-295.

Shewan D, Berry M, Cohen J (1995) Extensive regeneration in vitro by early embryonic neurons on immature and adult CNS tissue. J Neurosci 15:2057-2062.

Skene JH, Willard M (1981a) Changes in axonally transported proteins during axon regeneration in toad retinal ganglion cells. J Cell Biol 89:86-95.
Skene JH, Willard M (1981b) Axonally transported proteins associated with axon growth in rabbit central and peripheral nervous systems. J Cell Biol 89:96-103.

Smith GM, Hale JH (1997) Macrophage/Microglia regulation of astrocytic tenascin: synergistic action of transforming growth factor-beta and basic fibroblast growth factor. J Neurosci 17:9624-9633.

So KF, Aguayo AJ (1985) Lengthy regrowth of cut axons from ganglion cells after peripheral nerve transplantation into the retina of adult rats. Brain Res 328:349-354.

Stewart J, Weir DM (1989) Carbohydrates as recognition molecules in macrophage activities. J Clin Lab Immunol 28:103-108.

Stichel CC, Hermanns S, Luhmann HJ, Lausberg F, Niermann H, D'Urso D, Servos G, Hartwig HG, Muller HW (1999) Inhibition of collagen IV deposition promotes regeneration of injured CNS axons. Eur J Neurosci 11:632-646.

Thanos S, Mey J, Wild M (1993) Treatment of the adult retina with microglia-suppressing factors retards axotomy-induced neuronal degradation and enhances axonal regeneration in vivo and in vitro. J Neurosci 13:455-466.

Villegas-Perez MP, Vidal-Sanz M, Bray GM, Aguayo AJ (1988) Influences of peripheral nerve grafts on the survival and regrowth of axotomized retinal ganglion cells in adult rats. J Neurosci 8:265-280.

Wen R, Song Y, Cheng T, Matthes MT, Yasumura D, LaVail MM, Steinberg RH (1995) Injury-induced upregulation of bFGF and CNTF mRNAS in the rat retina. J Neurosci 15:7377-7385.

Wodarczyk L, Merrill VK, Perry GW (1997) Differential regulation of fast axonally transported proteins during the early response of rat retinal ganglion cells to axotomy. J Neurochem 68:1114-1123.

Wouters BC, Bock-Samson S, Little K, Norden JJ (1998) Up-regulation of fast-axonally transported proteins in retinal ganglion cells of adult rats with optic-peroneal nerve grafts. Mol Brain Res 53:53-68.

Xia Y, Vetvicka V, Yan J, Hanikyrova M, Mayadas T, Ross GD (1999) The beta-glucan-binding lectin site of mouse CR3 (CD11b/CD18) and its function in generating a primed state of the receptor that mediates cytotoxic activation in response to iC3b-opsonized target cells. J Immunol 162:2281-2290. 